\title{
Das Elektrokardiogramm des gesunden und kranken Menschen
}

\author{
von \\ Prof. Dr. Friedrich Kraus und Prof. Dr. Georg Nicolai \\ Direktor \\ Assistent \\ der II. medizinischen Klinik (Berlin)
}

Mit zahlreichen zum Teil mehrfarbigen Figuren

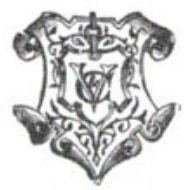

Leipzig

Verlag von Veit \& Comp.

1910 
Druck von Metzger \& Wittig in Leipzig. 
ZUR ERÖFHNUNG DES NEUBAUES DER II. MEDIZINISCHEN KLINIK 
